\title{
Low-Profile Neuroform Atlas Stent-Assisted Coiling of Intracranial Aneurysms: Single-Center Initial Experience
}

\author{
Somnath Pan ${ }^{1}$ Santhosh Kumar Kannath ${ }^{1} \quad$ Jayadevan Enakshy Rajan ${ }^{1}$
}

\author{
${ }^{1}$ Department of Imaging Sciences and Interventional Radiology, \\ Neurointervention Center, Sree Chitra Tirunal Institute of Medical \\ Sciences and Technology, Trivandrum, Kerala, India
}

\begin{abstract}
Address for correspondence Santhosh Kumar Kannath, MD, PDCC, Department of Imaging Sciences and Interventional Radiology, Neurointervention Center, Sree Chitra Tirunal Institute of Medical Sciences and Technology, Trivandrum 695011, Kerala, India (e-mail: drsanthoshkannath@gmail.com).
\end{abstract}

\begin{abstract}
Keywords

- intracranial aneurysms

- low-profile stent

- Neuroform Atlas stent
\end{abstract}

Background Neuroform Atlas stent is a relatively new device used for stent-assisted coiling (SAC) of wide-necked intracranial aneurysms.

Purpose To elaborate the initial experience in a single center to assess the efficacy and initial results of Neuroform Atlas for SAC of intracranial aneurysms.

Methods Between February 2017 and September 2018, eight patients (five females, three males; mean age 56 years) underwent SAC with Neuroform Atlas.

Results Five unruptured and three ruptured wide-necked aneurysms were treated with Neuroform Atlas SAC. Immediate complete occlusion modified Roy-Raymond class 1 (MRRC 1 ) or mild neck residue class 2 (MRRC 2) was achieved in three patients and five other patients had minimal residual interstitial filling of the aneurysm (MRRC 3b). One patient with ruptured intracranial aneurysm succumbed to the illness in the first postoperative day due to massive rebleed. Other seven patients remained clinically asymptomatic in the follow-up period. Patent stent was noted at three to seven months follow-up magnetic resonance angiography (MRA) in five patients. Complete occlusion of the aneurysm was noted in three patients, and minimal residual aneurysm was seen in two patients.

Conclusion Neuroform Atlas stent is safe and effective in achieving good angiographic outcome in complex intracranial aneurysms.

\section{Introduction}

Endovascular coiling is a safe and effective treatment option for the treatment of both ruptured and unruptured intracranial aneurysms. Expandable stents have broadened the spectrum of endovascular treatment of wide-necked and complex intracranial aneurysms by preventing coil protrusion into parent artery and allowing denser coil packing. ${ }^{1,2}$ Compared with the older-generation stents that required large-profile microcatheter for intracranial access, recently introduced low-profile self-expanding stents are compatible with the routine coiling catheters or intracranial balloon catheters with 0.017-in luminal

received

November 26, 2018

accepted after revision

January 11, 2019

published online

April 22, 2019 diameter. This mitigates the challenges associated with stent navigation in tortuous arteries or into distal intracranial location. The different low-profile stents available in the market include Low-profile Visualized Intraluminal Support Junior (LVIS Jr) (MicroVention, Terumo), LEO Baby (Balt), and Neuroform Atlas (Stryker Neurovascular). Low-profile stents are recommended for wide-necked aneurysms with dome-to-neck ratio $<2$ or neck diameter $>4 \mathrm{~mm}$ in parent vessels with diameter $<3 \mathrm{~mm}$. ${ }^{3,4}$

Neuroform Atlas, a newly introduced laser cut nitinol, self-expanding, hybrid/predominantly open-cell stent, is the evolution of Neuroform EZ supposing to ease the navigability of the system into intracranial arteries, through

\section{License terms}

(요 (1) $\odot \circledast$ 
a low-profile 0.0165 - or 0.017 -in (distal inner diameter) delivery microcatheter. The stent is available in diameter of 3,4 , and $4.5 \mathrm{~mm}$ intended for the artery diameter of 2-3, 3-4, and 4-4.5 mm, respectively. All stent sizes can be delivered through the same microcatheter. The stent has three radiopaque markers at both proximal and distal ends. The cell size is smaller compared with previous-generation Neuroform stents, which allows better coil retention and compaction. Neuroform Atlas stent has open-cell configurations in the distal and mid-segments and closed cell design in proximal part. Because of predominant opencell design, the stent is not resheathable. Neuroform Atlas is a magnetic resonance-conditional stent and patients can be safely scanned in 3 Tesla magnetic resonance scanner immediately after placement of this stent.

Only a few studies reporting the efficacy and clinical outcome of endovascular aneurysm treatment with Neuroform Atlas stent have been published so far., ${ }^{5,6}$ This observational study is aimed at describing the initial single-center experience and intermediate outcome of this low-profile stent in the management of complex intracranial aneurysms.

\section{Materials and Methods}

\section{Patient Characteristics}

Eight patients with intracranial wide neck or branch vessel incorporating aneurysms were treated with stent-assisted coiling (SAC) between February 2017 and September 2018 with Neuroform Atlas stent (-Table 1). Seven patients were treated primarily with this technique whereas in one case of balloon-assisted coiling of the aneurysm, stent was deployed as a bail-out procedure for coil prolapse and subsequent flow compromise.

\section{Endovascular Treatment and Medications}

To prevent acute stent thrombosis, dual antiplatelets aspirin $150 \mathrm{mg}$ and clopidogrel $75 \mathrm{mg}$ was given 5 days prior to the procedure in cases of unruptured intracranial aneurysms. If the stent was used as a bail-out maneuver or in cases of ruptured aneurysm, a GPIIb/IIIa inhibitor infusion (tirofiban infusion at $0.1 \mu \mathrm{g} / \mathrm{kg} / \mathrm{min}$ IV for 12 hours) was administered soon after deployment of the stent and securing the aneurysm with coiling. All the procedures were performed under general anesthesia and through femoral arterial access. Systemic heparinization was achieved to maintain an activated clotting time of 250 to 300 seconds. Triple coaxial system of 6F guide catheter (Neuron, Penumbra, Inc.) through a 7F long sheath (Flexor sheath, Cook Medical) was taken into the target artery. Echelon 10 microcatheter (Covidien/ Medtronic) over Traxcess 14 microguidewire (MicroVention, Terumo) was used to access the intracranial artery distal to the aneurysm, where the stent was intended to be deployed and Neuroform Atlas stent was deployed by gradual withdrawing of the microcatheter. Technical success was defined as ability to accurately deploy the stent in desired location with expansion and good wall apposition. The aneurysm was subsequently coiled using bare platinum coils by jailing technique or by cannulation of stent cells after deployment till complete obliteration was achieved. All patients underwent Dyna computed tomography (CT) immediately after the procedure to exclude any hemorrhage. Clopidogrel was discontinued after 6 weeks of treatment and aspirin was continued lifelong. The patients were followed up at 1,3 , and 6 months and yearly thereafter. Noncontrast magnetic resonance angiography (MRA) (silent and time of flight MRA in 3 Tesla MRI) was obtained after 3 to 6 months of procedure, and in case of significant residual or recurrent aneurysms, digital subtraction angiography (DSA) was performed.

Table 1 Patient, aneurysm, and Neuroform Atlas stent characteristics

\begin{tabular}{|c|c|c|c|c|c|c|c|c|}
\hline $\begin{array}{l}\text { Patient/ } \\
\text { aneurysm } \\
\text { number }\end{array}$ & $\begin{array}{l}\text { Age } \\
(y) / \text { sex }\end{array}$ & $\begin{array}{l}\text { Aneurysm } \\
\text { location and } \\
\text { status }\end{array}$ & $\begin{array}{l}\text { Clinical } \\
\text { presentation }\end{array}$ & $\begin{array}{l}\text { Aneurysm } \\
\text { size (mm) }\end{array}$ & $\begin{array}{l}\text { Neck } \\
(\mathrm{mm})\end{array}$ & $\begin{array}{l}\text { Immediate } \\
\text { MRRC }\end{array}$ & $\begin{array}{l}\text { Stent } \\
\text { size }(\mathrm{mm} \\
\times \mathrm{mm})\end{array}$ & $\begin{array}{l}\text { Follow-up } \\
\text { MRA (time and } \\
\text { outcome) }\end{array}$ \\
\hline 1 & $55 / F$ & $\begin{array}{l}\text { Basilar top } \\
\text { Unruptured }\end{array}$ & $\begin{array}{l}\text { Chronic } \\
\text { headache }\end{array}$ & $12 \times 15.6$ & 6.5 & 1 & $4 \times 30$ & $\begin{array}{l}6 \text { mo, no residual } \\
\text { aneurysm }\end{array}$ \\
\hline 2 & $67 / F$ & $\begin{array}{l}\text { Basilar top } \\
\text { Ruptured }\end{array}$ & $\begin{array}{l}\text { Acute severe } \\
\text { headache }\end{array}$ & $5.3 \times 8.4$ & 6.6 & $3 a$ & $4 \times 24$ & $\begin{array}{l}\text { Death due to } \\
\text { rebleed }\end{array}$ \\
\hline 3 & $67 / M$ & $\begin{array}{l}\text { Basilar top } \\
\text { Unruptured }\end{array}$ & $\begin{array}{l}\text { Gait } \\
\text { disturbance }\end{array}$ & $10 \times 7$ & 5 & $3 a$ & $4 \times 30$ & $\begin{array}{l}4 \text { mo, no residual } \\
\text { aneurysm }\end{array}$ \\
\hline 4 & $70 / \mathrm{M}$ & $\begin{array}{l}\text { ACOM } \\
\text { Ruptured }\end{array}$ & $\begin{array}{l}\text { Acute severe } \\
\text { headache }\end{array}$ & $6 \times 5$ & 4 & 2 & $4 \times 24$ & $\begin{array}{l}7 \text { mo, minimal } \\
\text { residual neck }\end{array}$ \\
\hline 5 & $43 / F$ & $\begin{array}{l}\text { Left carotid cave } \\
\text { Unruptured }\end{array}$ & Migraine & $4.7 \times 4.6$ & 4.9 & $3 a$ & $4.5 \times 21$ & $\begin{array}{l}6 \text { mo, no residual } \\
\text { aneurysm }\end{array}$ \\
\hline 6 & $53 / F$ & $\begin{array}{l}\text { Basilar trunk } \\
\text { Ruptured }\end{array}$ & $\begin{array}{l}\text { Acute severe } \\
\text { headache }\end{array}$ & $5.3 \times 5$ & 5.5 & $3 a$ & $4 \times 21$ & $\begin{array}{l}3 \text { mo, minimal re- } \\
\text { sidual aneurysm }\end{array}$ \\
\hline 7 & $50 / \mathrm{F}$ & $\begin{array}{l}\text { Right PCA-PCOM } \\
\text { Ruptured }\end{array}$ & $\begin{array}{l}\text { Acute severe } \\
\text { headache }\end{array}$ & $5 \times 5$ & 5 & 2 & $4 \times 24$ & - \\
\hline 8 & $60 / M$ & $\begin{array}{l}\text { Basilar trunk } \\
\text { Unruptured }\end{array}$ & $\begin{array}{l}\text { Acute } \\
\text { giddiness }\end{array}$ & $10 \times 11.5$ & 7.7 & $3 a$ & $4.5 \times 30$ & - \\
\hline
\end{tabular}

Abbreviations: ACOM, anterior communicating artery; F, female; M, male; MRA, magnetic resonance angiography; MRRC, modified Raymond-Roy classification; PCA, posterior cerebral artery; PCOM, posterior communicating artery. 


\section{Results}

Eight patients (five females and three males with femaleto-male ratio of 1.7 ) with age ranging from 50 to 70 years (mean age 58 years) were included in the study. There were four patients of ruptured and four patients of unruptured aneurysms.

Deployment of Neuroform Atlas stent as desired and opening-up of the stent were possible in all the cases achieving $100 \%$ technical success rate. Coiling of the aneurysms was performed by jailing technique in all the cases. In one patient, bail-out stenting was necessitated due to coil prolapse and resultant flow compromise ( - Fig. 1). In one case with very wide-neck aneurysm, shelf technique of the stent was performed to improve the coverage of neck of the saccular basilar top bifurcation aneurysm, thus obviating the need for complex Y-stent maneuvers (-Fig. 2).

Immediate complete occlusion (modified Raymond-Roy class 1 [MRRC 1]) was achieved in one (12.5\%) patient, near-complete occlusion was seen in other seven (88\%) patients with residual neck in two (MRRC 2) patients and minimal residual interstitial filling of the aneurysm in rest of the five patients (MRRC 3a). ${ }^{7}$ There were no thromboembolic complications noted during the procedure. One patient showed neurologic deterioration in the first postoperative day due to massive rebleed and the patient

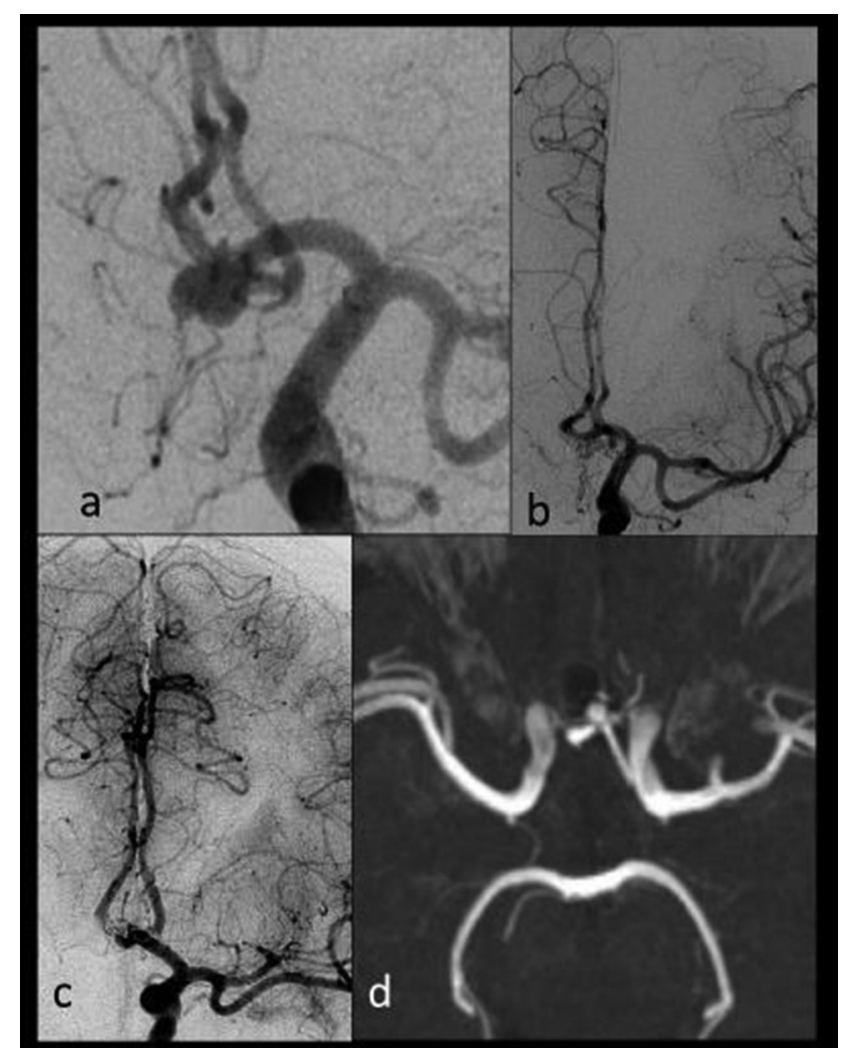

Fig. 1 A 70-year-old man (case 4) with wide-necked ruptured ACOM aneurysm as shown in DSA image (a). Because of coil prolapse, there is stagnant flow in left $A 2$ and perfusion defect in left ACA territory (b). Post-deployment of Atlas stent, there is restoration of flow (c) noted and MRA (d) after 6 months revealed minimal residual filling of the neck of the aneurysm. finally succumbed to the illness. The other patients remained clinically asymptomatic in the follow-up period. No other minor or major adverse events occurred on follow-up.

Persistent patent stent was noted in 3 to 7 months follow-up MRA in five patients. Complete occlusion of the aneurysm was noted in three (60\%) patients and minimal residual aneurysm in two (40\%) patients.

\section{Illustrated Cases}

Case 1

A 70-year-old male patient presented with acute-onset severe headache was found to have acute subarachnoid hemorrhage $(\mathrm{SAH})$, predominantly in the anterior interhemispheric fissure. DSA revealed a wide-necked anterior communicating artery (ACOM) aneurysm, measuring $6 \mathrm{~mm} \times 5 \mathrm{~mm}$ with neck of $4 \mathrm{~mm}$ incorporating both A2 anterior cerebral arteries. In view of ruptured status of the aneurysm, coiling under balloon assistance was initially planned, and the residual aneurysm, if present, was considered for definitive management at later date using stent assistance. During positioning of last coil inside the aneurysm, there was prolapse of earlier deployed coil into left A2 segment, resulting in progressive occlusion of the artery. The left A2 was then cannulated

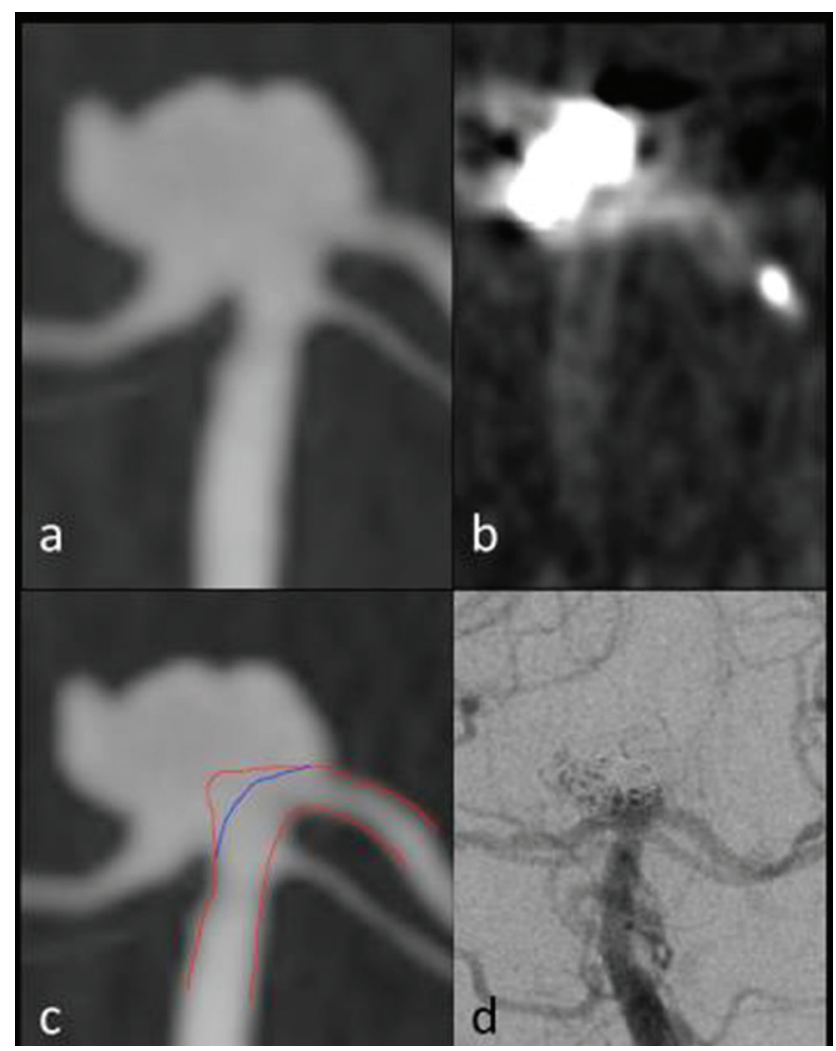

Fig. 2 A 67-year-old female patient with sudden-onset severe headache, found to have ruptured basilar top aneurysm measuring $5.3 \mathrm{~mm}$ $\times 8.4 \mathrm{~mm}$ and neck of $6.6 \mathrm{~mm}$, with incorporation of bilateral posterior cerebral arteries in 3D RA coronal image (a). A 4-mm $\times 24 \mathrm{~mm}$ sized stent is deployed with shelf technique (b). There is reduction in residual neck by $1.7 \mathrm{~mm}$ as depicted by Atlas stent in red as against other stents in blue line (c). Post-coiling angiogram (d) showed residual neck filling. 
using a Headway duo microcatheter (Microvention, Terumo) and navigated into left $\mathrm{A} 2$ segment, through which a Neuroform Atlas stent $(4 \times 24 \mathrm{~mm})$ was deployed from left A2 segment to left A1 segment by unsheathing. Tirofiban infusion was initiated following the stent deployment. Check angiogram revealed restoration of the artery with minimal residual filling of neck of the aneurysm (MRRC 2). The patient was neurologically stable at the time of discharge, and a follow-up magnetic resonance imaging (MRI) revealed minimal residual neck of aneurysm at 6 months (-Fig. 1)

\section{Case 2}

A 67-year-old female patient presented with acute-onset severe headache was found to have acute SAH (modified Fisher grade 4), predominantly in the prepontine cistern and bilateral sylvian fissures. DSA revealed irregular-shaped saccular basilar top aneurysm, measuring $5 \mathrm{~mm} \times 8 \mathrm{~mm}$ with neck of $6.5 \mathrm{~mm}$ incorporating both posterior cerebral arteries (PCAs). Though Y-stent option would have been ideal to protect both PCA, it was not considered due to the requirement of rigorous platelet activity suppression, consequently increasing the hemorrhagic risk. Hence, the patient underwent Neuroform Atlas stent-supported coiling with shelf technique ( - Fig. 2). Through the Echelon microcatheter, Neuroform Atlas $4 \mathrm{~mm} \times$ $24 \mathrm{~mm}$ stent was deployed with its distal end in the left P1 PCA and proximal end in the basilar artery, bridging the neck of the aneurysm and jailing the second microcatheter. Subsequently the aneurysm was coiled, and Tirofiban infusion was initiated following the stent deployment and securing the dome of the aneurysm. Check angiogram revealed residual neck and preserved flow in bilateral PCAs. Six hours after the procedure, her Glasgow coma scale (GCS) deteriorated and an urgent MRI revealed massive rebleed, to which patient succumbed. Persistent residual neck in the setting of antiplatelet suppression was assumed to be the cause of rebleed.

\section{Discussion}

The intracranial stents are generally indicated when the aneurysm shows unfavorable features such as wide neck $(\geq 4$ $\mathrm{mm}$ ) or dome-to-neck ratio $<1.3$. Since the first publication about SAC to prevent coil protrusion from aneurysm sac by Higashida et al, several types of intracranial stents have come into use. With bridging of the neck of the aneurysms, self-expandable stents allow denser coil packing and may also improve the occlusion rate through a combinations of flow diversion, parent vessel straightening, and fibroelastic tissue formation along neck of the aneurysms. ${ }^{8,9}$ Across different studies of SAC, immediate complete occlusion rate varied from 45 to $60 \%$ and procedural complications varied from 6.2 to $12 \%$. Higher rate of complications (up to $25 \%$ ) were noted in cases of acutely ruptured aneurysms. ${ }^{10}$ Recently introduced low-profile self-expandable stents widened the scope of treatment of wide-necked distal small vessel aneurysms as well as compatibility with low-profile microcatheter to ease the access and lesser strain on the parent vessels while navigating multiple devices. In a large series of wide-neck intracranial aneurysms treated with LEO Baby stent, high technical success rate of $97.5 \%$ and complete occlusion of aneurysm of $75 \%$ were achieved. The procedure related complication rate was $11.3 \%$ with permanent morbidity of $3.8 \%{ }^{3}$ In a series of 41 aneurysms by Poncyljusz et al, using another low-profile stent, LVIS Jr, complete occlusion was achieved in $85 \%$ of cases and minor adverse events were noted in $4 \%$ of patients. ${ }^{4}$ LVIS Jr stents were successfully deployed with good opening in 37 patients achieving 90\% technical success rate.

In our series, Neuroform Atlas stent could be successfully deployed as desired in all cases with proper alignment and apposition to parent vessels across the neck of the aneurysms. This is similar to $100 \%$ deployment accuracy shown in two other studies of SAC with Neuroform Atlas and similar or better than the results with other low-profile stents. ${ }^{3,4}$ In all seven cases of primary SAC, satisfactory coil packing could be achieved with no incidences of coil prolapse. Immediate complete or near-complete occlusion was achieved in all the cases. Three of the five cases with immediate postprocedural residual interstitial filling (MRRC 3a) were the cases with ruptured aneurysms where coil packing density was intentionally kept low to prevent intraprocedural rupture.

Using Neuroform Atlas stent in a series of 37 aneurysms, Ulfert et al achieved immediate complete occlusion of the aneurysms in $84 \%$ cases. No major adverse events or deaths were noted in their study, and only one (3\%) patient developed transient ischemic attack in immediate post-procedure period. At a median follow-up of 6 months, 93\% of the cases showed complete occlusion and neck remnant was seen in $7 \%$ of the follow-up cases. Cay et al, in their series of 55 cases of Neuroform Atlas SAC, achieved 94\% Raymond-Roy score of 1 or 2 aneurysm occlusion at mean follow-up of 7.9 months, with no major clinical events. In our study, immediate periprocedural morbidity and mortality were noted in one (12.5\%) of our case of ruptured basilar artery aneurysm due to rebleed. No other major or minor adverse events occurred in rest of the seven cases. Clinical safety was achieved in $87.5 \%$ of cases, which is better than SAC with previous generations of stents and comparable to the results of other two recent studies of Neuroform Atlas SAC. Five patients were followed up with MRA between 3 and 7 months post-coiling, which revealed no incidences of stent occlusion or thrombosis, no proximal or distal migration of the stent, complete obliteration of the aneurysms in three $(60 \%)$ cases, and minimal residual aneurysms in two (40\%) cases.

Neuroform Atlas is a self-expanding, open-cell, nitinol stent, with flared ends and three radiopaque marker bands on its proximal and distal end. It has four interconnects between the central stent segments, designed to provide support of the coil mass within the aneurysm and minimize stent deflection. Open-cell design aids stent conformability and trackability. Open 12 cell structure design at the proximal half of the stent shaft provides better scaffolding with reduced gator backing phenomenon. Open eight cell structural elements in distal half of the stent shaft provide support and anchoring. Being a laser cut design shortening effect after deployment of the stent is negligible. Compared with the other intracranial stents, Neuroform Atlas like other low-profile stents can be delivered through a small-profile microcatheter (0.017 in), 
and because of this advantage, these stents can be deployed even in distal small intracranial arteries. Also, the profile of the stent remains same across different stent sizes. Though there are studies on other low-profile braided stents such as LVIS Jr or LEO Baby stents, a very few studies in the literature are yet available on the efficacy of Neuroform Atlas stents in the treatment of aneurysms. Being a laser cut stent with opencell design, the stent could be easily deployed by unsheathing of the microcatheter, and once the first crown is released, it anchors the stent and prevents undue migration of the stent during rest of the deployment. Because the cell size is large, it allows easy cannulation of microcatheter through the stent struts into the aneurysm or bifurcation branch. Also, the proximal closed cell design offers stent stability during lumen recrossing. In braided stents, to cannulate the aneurysm, microcatheter is advanced through the struts, which will displace the wire braid and allow catheterization. However, there is a theoretical risk of sudden catheter advancement during this maneuver and resultant aneurysm perforation especially if the aneurysm is very small. Also, the deployment of the braided low-profile stents requires expertise to ensure optimal wall apposition and adequate neck coverage, which may not be the case for Neuroform Atlas. ${ }^{4}$ We did not experience any difficulty during deployment of stent or while cannulation of the aneurysm suggesting a relatively flat learning curve associated with this stent. Because of the open-cell design, Neuroform Atlas stent is not resheathable once the first crowns are deployed. Therefore, if the stent position is not accurate across the neck of the aneurysm, unlike other stents, Neuroform Atlas stent cannot be redeployed. However, we did not experience any improper deployment of the stent. Another advantage is the availability of sizes and lengths ranging from 3-4.5 $\mathrm{mm}$ and $15-30 \mathrm{~mm}$, respectively, which could be positioned in arteries of size 2 till $4.5 \mathrm{~mm}$. Because of this versatile range, it could be deployed in proximal large and distal small intracranial arteries, as demonstrated in our study. Other braided stent size varies from 2 to $2.5 \mathrm{~mm}$ (LEO Baby) or 2.5 to $3.5 \mathrm{~mm}$ (LVIS Jr). ${ }^{3.4}$ Similar to shelf technique described with braided stents, hybrid design of Atlas stent permits this maneuver, thus allowing better neck coverage especially in bifurcation aneurysms as demonstrated in one of the cases ( - Fig. 2). This technique obviates additional stents to preserve branch arteries. Compared with the braided stents, additional flow diversion effect might be lacking in Neuroform Atlas stent; however, its impact on aneurysm occlusion and aneurysm healing is currently unknown.

Limitations of our study include small number of cases and short follow-up period. MRA may limit the assessment of the actual status of the aneurysm. Though only MRA was used for follow-up assessment, it has been shown to have good correlation with cerebral angiography in the follow-up evaluation of stent-supported coiled aneurysms. ${ }^{11,12}$

\section{Conclusion}

In our small series, we observed that Neuroform Atlas stent is a safe and effective device for treatment of complex intracranial aneurysms with durable intermediate outcomes.
Because of the ease of deployment and low-profile nature, it couldbe considered, if flow diversion effect of stent is not desired.

\section{Contributions of Authors}

- SP-data collection, data analysis, data interpretation, manuscript preparation

- SKK-concept and design, analysis, data interpretation, manuscript preparation and revision

- JER-manuscript preparation, critical revision

\section{Conflicts of Interest}

The authors have no personal or financial conflict of interest to disclose.

\section{References}

1 Benitez RP, Silva MT, Klem J, Veznedaroglu E, Rosenwasser RH. Endovascular occlusion of wide-necked aneurysms with a new intracranial microstent (Neuroform) and detachable coils. Neurosurgery 2004;54(6):1359-1367, discussion 1368

2 Biondi A, Janardhan V, Katz JM, Salvaggio K, Riina HA, Gobin YP. Neuroform stent-assisted coil embolization of wide-neck intracranial aneurysms: strategies in stent deployment and midterm follow-up. Neurosurgery 2007;61(3):460-468, discussion 468-469

3 Aydin K, Arat A, Sencer S, Barburoglu M, Men S. Stent-assisted coiling of wide-neck intracranial aneurysms using low-profile LEO baby stents: initial and midterm results. AJNR Am J Neuroradiol 2015;36(10):1934-1941

4 Poncyljusz W, Biliński P, Safranow K, et al. The LVIS/LVIS Jr. stents in the treatment of wide-neck intracranial aneurysms: multicentre registry.J NeuroIntervent Surg 2015;7(7):524-529

5 Ulfert C, Pham M, Sonnberger M, et al. The Neuroform Atlas stent to assist coil embolization of intracranial aneurysms: a multicentre experience. J Neurointerv Surg 2018;10(12):1192-1196

6 Cay F, Peker A, Arat A. Stent-assisted coiling of cerebral aneurysms with the Neuroform Atlas stent. Interv Neuroradiol 2018;24(3):263-269

7 Mascitelli JR, Moyle H, Oermann EK, et al. An update to the Raymond-Roy occlusion classification of intracranial aneurysms treated with coil embolization. J Neurointerv Surg 2015;7(7):496-502

8 Piotin M, Blanc R, Spelle L, et al. Stent-assisted coiling of intracranial aneurysms: clinical and angiographic results in 216 consecutive aneurysms. Stroke 2010;41(1):110-115

9 Lawson MF, Newman WC, Chi YY, Mocco JD, Hoh BL. Stent-associated flow remodeling causes further occlusion of incompletely coiled aneurysms. Neurosurgery 2011;69 (3):598-603, discussion 603-604

10 Chalouhi N, Jabbour P, Singhal S, et al. Stent-assisted coiling of intracranial aneurysms: predictors of complications, recanalization, and outcome in 508 cases. Stroke 2013;44(5):1348-1353

11 Irie R, Suzuki M, Yamamoto M, et al. Assessing blood flow in an intracranial stent: a feasibility study of MR angiography using a silent scan after stent-assisted coil embolization for anterior circulation aneurysms. AJNR Am J Neuroradiol 2015;36(5):967-970

12 Cho WS, Kim SS, Lee SJ, Kim SH. The effectiveness of 3T timeof-flight magnetic resonance angiography for follow-up evaluations after the stent-assisted coil embolization of cerebral aneurysms. Acta Radiol 2014;55(5):604-613 